\title{
HÉRNIA ENCARCERADA EM ORIFÍCIO DE TROCARTE LATERAL DIAGNOSTICADAPOR TOMOGRAFIA COMPUTADORIZADA
}

\section{INCARCERATED HERNIA IN A LATERAL TROCAR SITE DIAGNOSED BY COMPUTED TOMOGRAPHY}

\author{
Gustavo Lopes de Carvalho, TCBC-PE ${ }^{1}$; Antonio Carlos Bacelar Nunes Filho²; \\ Gerson Cesar Brasil Junior ${ }^{2}$
}

\section{INTRODUÇÃO}

$\mathrm{O}$ advento da cirurgia minimamente invasiva resultou na diminuição do aparecimento de hérnias inciosionais. Apesar de baixa, esta incidência está relacionada com a localização do sítio de punção e o tamanho do trocarte, sendo maior no orifício do trocarte umbilical e quando este possui diâmetro de $10 \mathrm{~mm}$ ou mais. O presente caso relata uma hérnia encarcerada pós-laparoscopia de difícil diagnóstico em que a tomografia computadorizada foi essencial na elucidação do mesmo.

\section{RELATO DO CASO}

Paciente de 55anos, sexo feminino, obesa, portadora de mioma uterino de grande volume $-1.200 \mathrm{~cm}^{3}$, foi submetida à histerectomia videolaparoscópica. O procedimento foi realizado com sucesso e a paciente recebeu alta no $1^{\circ}$ dia pósoperatório (DPO) sem intercorrências. Três dias após, retornou ao hospital com queixas de vômitos e dor abdominal em cólicas. Ao exame físico constatou-se distensão abdominal, dor abdominal difusa à palpação e ausência de irritação peritoneal. A radiografia de abdome foi compatível com obstrução intestinal alta. Foi iniciado tratamento clínico com regressão do quadro agudo, e alta hospitalar após 48 horas. No $18^{\circ} \mathrm{DPO}$, após três episódios de agudização e remissão espontânea de sintomatologia compatível com semi-oclusão intestinal, optou-se por realizar uma tomografia computadorizada (TC) de abdome com contraste oral, que detectou hérnia encarcerada no orifício do trocarte lateral direito de $10 \mathrm{~mm}$ de diâmetro (Figura1). A paciente foi submetida à abordagem videolaparoscópica, tendo sido encontrada alça viável de intestino delgado no orifício herniário. Procedeu-se à redução do conteúdo herniário e fechamento vídeo-assistido da aponeurose do orifício do trocarte. A paciente evoluiu sem intercorrências recebendo alta após $24 \mathrm{~h}$ da cirurgia.

\section{DISCUSSÃO}

Hérnia Incisional (HI) é uma complicação freqüente das cirurgias convencionais abertas, sendo encontrada em 5 a $15 \%$ dos casos. Esta prevalência varia conforme os diferentes estudos, o subgrupo de pacientes estudados e a duração do acompanhamento ${ }^{1}$. É achado comum encontrar dentro do saco herniário parte do grande omento bem como do intestino delgado, sendo este causa freqüente de obstrução intestinal $^{1}$. O advento da cirurgia laparoscópica resultou em diminuição da incidência de hérnias, porém não extinguiu este tipo de complicação, sendo o primeiro caso de obstrução intestinal pós-laparoscopia descrito em $1974^{2}$.

Após cirurgias laparoscópicas a localização da HI dá-se preferencialmente na linha mediana, com diversos relatos descrevendo a existência de hérnia no orifício do trocarte umbilical, principalmente quando este possui $10 \mathrm{~mm}$ de diâmetro ou mais. No entanto, quando se trata de hérnia no orifício do trocarte lateral, este achado se torna incomum, com frequiência de $0,23 \%{ }^{3}$.

O diagnóstico de hérnia encarcerada geralmente é feito através do exame físico, mas no presente caso, o fato da paciente possuir um panículo adiposo espesso, dificultou o exame clínico e o diagnóstico definitivo só foi firmado após a realização de TC de abdome com contraste oral. Este exame

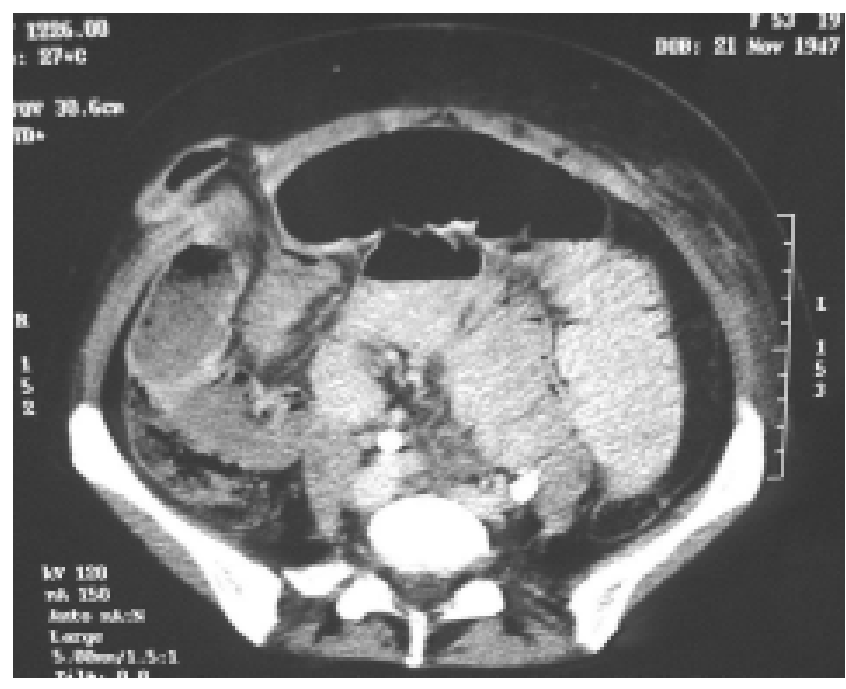

Figura 1 - Tomografia computadorizada de abdome com contraste oral, evidenciando hérnia encarcerada em orifício de trocarte lateral direito.

1. Doutor em Cirurgia pela UFPE; Membro Internacional do SAGES; Membro da SOBRACIL.

2. Acadêmico do Curso de Medicina da UPE.

Trabalho realizado na Faculdade de Ciências Médicas / UPE - Recife-PE e Clínica Cirúrgica Videolaparoscópica Gustavo Carvalho. 
também é de grande valia para a diferenciação entre hematoma de parede abdominal associado a íleo paralítico e hérnia encarcerada, pois um hematoma é uma complicação mais frequente que uma hérnia no pós-operatório imediato de uma laparoscopia. Desta forma pode-se evitar a drenagem inadvertida de uma hérnia encarcerada ${ }^{4}$.

A despeito de sua raridade, hérnia encarcerada em orifício de trocarte lateral não deve ser esquecida pelos cirurgiões como potencial responsável por casos de obstru- ção intestinal precoce, ocorrendo tipicamente entre o terceiro e sétimo dia pós-laparoscopia, sobretudo em pacientes obesos $^{5}$.

No intuito de evitar formação de HI, consideramos pertinente a sugestão do fechamento rotineiro da fáscia aponeurótica, não apenas no orifício do trocarte umbilical, como também nos orifícios dos trocartes laterais, principalmente quando estes se situarem abaixo da cicatriz umbilical e possuírem $10 \mathrm{~mm}$ de diâmetro ou mais ${ }^{1,3,4,5}$.

\begin{abstract}
Incisional hernia is an uncommon complication in laparoscopic surgery. The majority of the hernias are located in the umbilical site. Nevertheless, they can occur in the lateral trocar site, although they are rarely diagnosed. We report a case of a 55 year-old patient who underwent a videolaparoscopic hysterectomy and developed small bowel obstruction on the third postoperative day. This initially gave rise to the diagnosis of paralytic ileum. The definitive diagnosis of incarcerated hernia in the lateral trocar site was established after an abdominal computed tomography was performed (Rev. Col. Bras. Cir. 2005; 32(3): 163-164).

Key-words: Small Bowel Obstruction; Laparoscopic Surgery; Postoperative Complications; Videolaparoscopic Hysterectomy; Incisional Hernia; Computed Tomography.
\end{abstract}

\section{REFERÊNCIAS}

1. Bowrey DJ, Blom D, Crookes PF, et al. - Risk factors and the prevalence of trocar site herniation after laparoscopic fundoplication. Surg Endosc. 2001;15(7):663-6.

2. Schiff I, Naftolin F - Small bowel incarceration after uncomplicated laparoscopy. Obstet Gynecol. 1974;43(5): 674-5.

3. Kadar N, Reich H, Liu CY, et al. - Incisional hernias after major laparoscopic gynecologic procedures. Am J Obstet Gynecol. 1993;168(5):1493-5.

4. Reissman P, Shiloni E, Gofrit O, et al. - Incarcerated hernia in a lateral trocar site - an unusual early postoperative complication of laparoscopic surgery [Case report]. Eur J Surg. 1994;160(3):191-2.
5. Bender E, Sell H - Small bowel obstruction after laparoscopic cholecystectomy as a result of a Maydl's herniation of the small bowel through a trocar site. Surgery. 1996;119(4):480.

Endereço para correspondência:

Gustavo Carvalho, MD, PhD

Avenida Domingos Ferreira, 2776.

51020-030 - Recife - PE- BRASIL

Tel. 55(81) 3465- 7866

R-mail: gc@elogica.com.br 